\title{
Psychological Stress: A Predisposing and Exacerbating Factor in Periodontitis
}

\author{
Anna M. Spector ${ }^{1} \cdot$ Teodor T. Postolache ${ }^{1,2,3,4} \cdot$ Faisal Akram $^{1,5} \cdot$ Alison J. Scott $^{6} \cdot$ Abhishek Wadhawan $^{1,5}$. \\ Mark A. Reynolds ${ }^{7}$
}

Published online: 11 August 2020

(C) The Author(s) 2020

\begin{abstract}
Purpose of Review This review focuses on recent advances in our understanding of the interactions between psychological stress, the immune system, and periodontitis, including the dynamic role of host stress responses in altering immune function, altering the oral microbiome and biofilm formation, and promoting local and systemic disease progression.

Recent Findings Within the context of periodontal health and disease, stress leads to an impairment of effective antimicrobial defense, shifts in oral microbiome profiles toward more pathogenic gene expression and taxa composition, increased translocation, and biofilm formation. The link between stress and periodontitis is multiform and includes hypothalamic-pituitary-adrenal (HPA) axis and catecholamine activation, production of immune mediators of inflammation and, clinically, syndromes of depression, bipolar disorder, anxiety disorders, and sleep-wake disorders.

Summary Psychological stress appears to be an important modifiable risk factor for the development and progression of periodontitis and other periodontal diseases.
\end{abstract}

Keywords Periodontal disease $\cdot$ Stress $\cdot$ Microbiome $\cdot$ Inflammation $\cdot$ Sleep $\cdot$ Biofilm

\section{Introduction}

Inflammation is a prominent feature of common chronic diseases, including atherosclerosis, cancer, and periodontitis.

This article is part of the Topical Collection on Systemic Diseases

Mark A. Reynolds

mreynolds@umaryland.edu

1 Mood and Anxiety Program, Department of Psychiatry, University of Maryland School of Medicine, Baltimore, MD, USA

2 Rocky Mountain Mental Illness Research Education and Clinical Center (MIRECC), Denver, CO, USA

3 Military and Veteran Microbiome: Consortium for Research and Education (MVM-CoRE), Denver, CO, USA

4 VISN 5 Capitol Health Care Network Mental Illness Research Education and Clinical Center (MIRECC), Baltimore, MD, USA

5 Department of Psychiatry, Saint Elizabeths Hospital, Washington, DC, USA

6 Department of Microbial Pathogenesis, University of Maryland School of Dentistry, Baltimore, MD, USA

7 Department of Periodontics, School of Dentistry, University of Maryland, Baltimore, MD 21201, USA
Many modifiable risk factors, such as smoking, contribute to increases in systemic markers of inflammation, which can further modify gene regulation through a variety of biologic mechanisms [1]. Mounting evidence points to the ability of psychological stress to dysregulate the inflammatory response, promoting the development and progression of disease [2]. Moreover, evidence continues to expand our understanding of the reciprocal interaction between psychological well-being and overall physical health. The significance of this interplay is perhaps most evident when adaptive capacities are overloaded by environmental demands and events in times of psychological stress, referred to simply as "stress" in this article [3]. Stress is associated with the predisposition, precipitation, perpetuation, and exacerbation of many illnesses, as well as worsening morbidity and mortality [4]. Stress has been shown to induce and worsen inflammation, an underlying factor in many major chronic illnesses, including cardiovascular, metabolic, digestive, pulmonary, and rheumatologic illnesses as well as conditions with an infectious, allergic, autoimmune, or neoplastic etiology $[2,5]$.

For over 100 years, stress has been recognized as a predisposing factor in the development of necrotizing gingivitis (aka, Vincent's infection, trench mouth, acute necrotizing 
ulcerative gingivitis [6]). Necrotizing gingivitis was first extensively documented in military personnel exhibiting acute psychological stress, poor oral hygiene, and malnutrition. Necrotizing gingivitis is clinically characterized by rapid onset with associated pain, bleeding, and ulceration of the gingival interdental papilla. Spirochetes, Fusobacterium, and Bacteroides species are commonly recovered from gingival lesions [7].

Periodontitis is a prevalent condition, affecting nearly $50 \%$ of US adults [8], that often exhibits chronicity and periodicity in progression. This review focuses on recent advances in our understanding of the interactions between stress, the immune system, and periodontitis, including the dynamic role of host stress responses in impairing normal protective immune defenses, altering the oral microbiome and biofilm formation, and promoting local and systemic disease progression. Stress is a potentially important modifiable risk factor causally associated with exacerbation of periodontitis and other inflammatory periodontal diseases.

\section{Stress}

Stress is the activation of the brain's defensive motivational system to promote behaviors that protect the organism from perceived future danger; it is experienced when there is a mismatch between a person's coping ability (i.e., ability to adjust to or tolerate) and actual or perceived environmental events or demands, such as an imminent threatening stimulus or situation [2, 9]. Stress can stem from external events originating in the environment (e.g., loss of job), or from one's own perception of those experiences or thoughts. A person's coping ability is largely determined by the dynamic interaction between resiliency mechanisms and vulnerabilities, which are inherent or acquired at different stages of neurodevelopment. Coping skills usually help in achieving two goals: managing emotions and altering the relationship between the individual and the stressor [9]. Resilient individuals are able to "capacitate" strain, threats, and losses, often responding to stress with humor and optimism; they are able to "move on" [10]. On the other hand, early childhood adversity can increase vulnerability to a maladaptive stress response that imprints onto the immature brain in a way that lasts far into adulthood $[11 \bullet \bullet]$. Children exposed to chronic stress experience accelerated aging and increased prevalence of systemic illnesses, including ischemic heart disease and cancers as adults [11-14]. Social support and positive relationships can increase resiliency and improve children's ability to respond to stress in an effective way $[15,16]$.

\section{Clinical Implications of Stress}

It is important to note that stress is an active response and involves an organized system of communication between the brain and other organs, including endocrine and immune systems, to mobilize internal defenses for survival and safety $[17,18]$. However, a significant cumulative biological damage is incurred by the body as an unintended consequence of allostasis (i.e., behavioral or physiological process of achieving stability in response to stressors), which has been referred to as "allostatic load" [17, 18].

Among clinical outcomes of stress, depression displays the strongest association [3]. Stress may also lead to substance use, sleep deprivation, and poor eating habits. Systemic illnesses significantly associated with stress include metabolic disorders such as diabetes, cardiovascular disease, infectious diseases, autoimmune diseases, and periodontal disease [17, 19-29].

Several studies have found a positive relationship between life stressors and periodontitis [30-35, 36••]. Dental phobia is a specific life stressor that often leads to more advanced disease and poorer clinical outcomes because dental care is sought at later stages of disease requiring more invasive treatment [37]. In the following sections, we explore the mechanisms involved in the stress-periodontitis relationship.

\section{Stress and Periodontitis: The HPA Connection}

A fundamental question is how stress contributes to disease, such as periodontitis, and whether the relationship is reciprocal (see Fig. 1). A growing body of research has identified various systems and pathways that are responsive to stress and mediate the mind-brain-body relationship [5, 38, 39••, 40••, 41, 42]. Under physiological conditions, these stress pathways promote adaptation and survival via autonomic, endocrine, metabolic, and immune responses [17]. However, chronic stress can lead to dysregulation of these pathways which can lead to significant biological damage [4, 24, 43]. Specifically, the dysregulation of the HPA axis and immune system has been well established in the context of chronic stress.

The hypothalamic-pituitary-adrenocortical axis (HPA) and the sympathetic-adrenal-medullary (SAM) system are the two neuroendocrine substrates of stress. The paraventricular nucleus of the hypothalamus is activated in response to acute stress [44, 45], releasing arginine vasopressin and corticotropin-releasing hormone $(\mathrm{CRH})$ which, in turn, stimulate the pituitary gland to secrete adrenocorticotropic hormone (ACTH), activating the cortex of the adrenal gland to secrete cortisol $[42,46]$. Cortisol rises with stress, as do catecholamines, through the activation of the noradrenergic center in the locus coeruleus of the brainstem and the medulla of the adrenal gland, which releases epinephrine. Both cortisol and 
Fig. 1 Stress is associated with periodontal disease (periodontitis) through multiple complex underlying pathways, including activation of the HPA-axis, autonomic nervous system, and inflammatory cascades. Many of these pathways result in pathological responses to psychological stress, particularly in the absence of adequate coping skills and resilience, leading to the hyperactivation of the HPA-axis and autonomic nervous system. Mediators involved in these signaling cascades, such as cortisol, cytokines, and catecholamines, also exhibit the potential to influence the oral and gut microbiome and bacterial pathogenicity. Mental illness and sleep disorders appear to further exacerbate stress and periodontal disease through common pathways

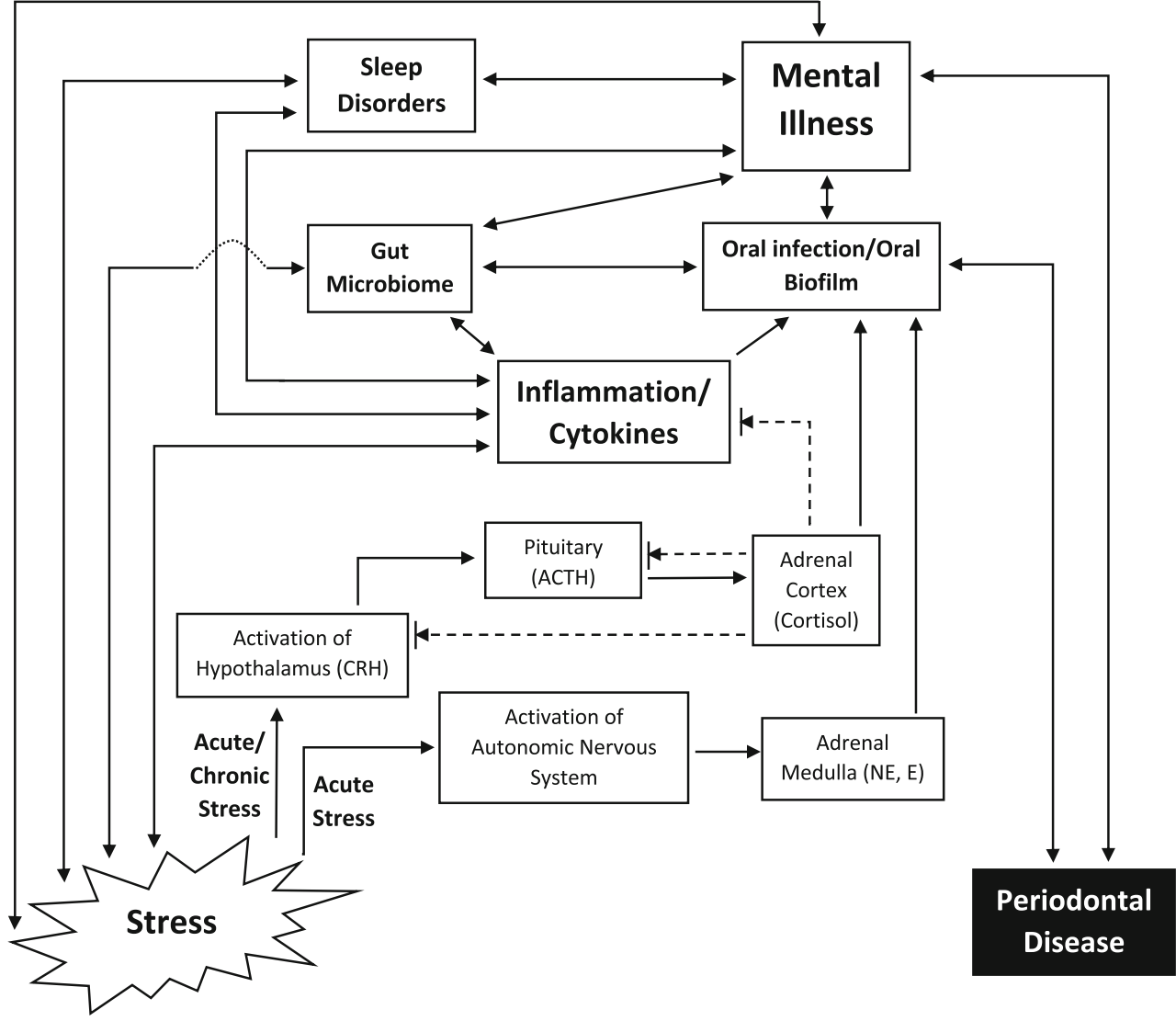

adrenergic molecules allow the body to respond to danger, real or perceived, by increasing vigilance, reactivity, and mobilizing the body's resources for sustaining physiological "fight or flight" [47].

Persistent dysregulation of the HPA axis caused by stress, and especially in terms of cortisol levels, is implicated in many illnesses, such as autoimmune diseases, cardiovascular disease, HIV/AIDS progression, upper respiratory tract infection, osteoporosis, obesity, and periodontitis [26, 30, 44, 45, 48]. Cortisol levels rise after acute stress, such as after the loss of a child, and rise even further when coping skills are ineffective [49]. With chronic stress, cortisol levels may still be high, but cortisol is no longer able to blunt the immune response as it does acutely. The cascade of inflammation is initiated leading to the increase of circulating proinflammatory cytokines and modulation of their action [4], but the action of cortisol is then generally thought to be ineffective at blocking inflammatory pathways due to glucocorticoid receptor resistance $[2,50]$.

Regulatory T cells ( $\mathrm{T}$ regs) suppress the inflammatory cascade, producing Transforming Growth Factor (TGF)- $\beta 1$ and Interleukin (IL)-10 as well as suppressing $\mathrm{CD}^{+}$and $\mathrm{CD} 8^{+}$ effector cell responses. Regulatory $\mathrm{T}$ cells are reduced in depression and the ratio of $\mathrm{T}$ regs to pro-inflammatory $\mathrm{T}$ cells is decreased with stress [51]. Additionally, a decrease in $\mathrm{T}$ regs has been shown in patients with atherosclerosis that are periodontally infected by Porphyromonas gingivalis ( $P$. gingivalis) [52].

Animal models have also been used to examine the effect of stress on the development and progression of periodontitis. Experimentally induced periodontitis in rats exposed to chronic stress was associated with increased blood glucose, plasma $\mathrm{ACTH}$, corticosterone and adrenaline, as well as more severe alveolar bone resorption, when compared to rats not exposed to chronic stress. This relationship is hypothesized to be enhanced through adrenergic pathways suggesting that adrenergic antagonists could be a pharmacological treatment for periodontitis [53, 54].

Clinically, Peruzzo et al. (2007) reported that the majority of studies ( 7 case-control studies, 6 cross-sectional studies, and 1 prospective clinical trial) that met inclusion criteria in a systematic review found a positive association between psychosocial stress and periodontal disease [55]. Similarly, in a cross-sectional study of 235 individuals, a positive correlation was found between salivary cortisol levels and the severity of periodontitis with adjustments for age, sex, oral hygiene, bleeding on probing, smoking, and stress inventory scores in adults 50 years and older [47]. In a systematic review of the relationship between periodontal status and cortisol levels in saliva, it was found that only 3 of the 6 studies measured stress, whereas the other study used cortisol as a proxy for stress [56]. In conclusion, a positive association has been 
found between cortisol levels and periodontal disease; however, causality cannot be inferred because of the crosssectional nature of all studies [56].

\section{Stress and Periodontitis: Role of Inflammation}

Inflammation provides another potential mechanistic link between stress and periodontitis. Experiments with animal models of stress in the form of infections, exposure to toxins, physical injury, restraint, social deprivation, or mother-infant separation have found long-term changes in certain molecular and cellular immune markers [4, 57-61]. With chronic stress, there is an increase in circulating neutrophils and functional immunosuppression through the modification of the T-helper 1 cell (Th-1) and T-helper 2 (Th-2) cell response, including changes in the ratio of the Th- 1 to Th- 2 cells, thereby diminishing the proliferation of $\mathrm{T}$ cells and the antibody response, respectively $[4,50,62]$. It has been hypothesized that chronic increases in cortisol leads to glucocorticoid receptor resistance (GCR) causing a decrease in immunosuppressive actions of cortisol on lymphocytes [2]. The ratio of Tregs (cells involved in regulation of the intensity and duration of inflammation after exposure to inflammation triggers) to proinflammatory $\mathrm{T}$ cells is also decreased with stress [51]. A meta-analysis has identified elevations of blood levels of IL6 , Tumor Necrosis Factor (TNF)- $\alpha$, IL- $1 \beta$, and C-reactive protein (CRP) in response to stress [63].

Pro-inflammatory mediators found in the gingival crevicular fluid are generally elevated in active or untreated periodontitis $[64,65]$. Given that chronic stress leads to dysregulation of the immune system, with increases in the levels of cytokines and other pro-inflammatory mediators [47, 56, 65, 66], the inflammation-mediated damage may be one plausible explanation of increased risk of periodontal disease in stress.

\section{Stress and Periodontitis: The Biofilm Connection}

As stress leads to decreased immunity and to increased susceptibility to infections and bacterial proliferation, the role of the oral microbiome has gained significant attention in the context of stress and periodontal disease. Periodontal disease is thought to be driven by a complex dysbiotic microbiota [67-69]. Indeed, several species of bacteria, in particular, "red complex" bacteria P. gingivalis, Tannerella forsythia, and Treponema denticola as well as Aggregatibacter actinomycetemcomitans are recognized as important pathogens in periodontitis [70]. These pathogens were isolated in the subgingival plaque of patients with periodontitis and found to correlate with levels of oxidative stress markers (8hydroxydeoxyguanosine and malondialdehyde) in saliva, with highest oxidative stress levels associated with the combination of the three red complex pathogens [71]. The persistence of the bacteria, as a component of dental plaque, results in a constant production of pro-inflammatory cytokines and other molecular mediators, which leads to extensive tissue destruction [66]. In particular, $P$. gingivalis has the ability to change the composition of plaque and the inflammatory milieu through one of the virulence factors of $P$. gingivalis, gingipains, which converts complement C5 to C5a, thereby inducing inflammation and also modulating the Toll-like receptor response, thus preventing leukocytes from being efficient killers [72]. Studies have shown a positive association between cortisol levels and the presence of $P$. gingivalis in subgingival plaques of localized periodontitis, after adjusting for age, sex, income, and smoking status [73]. P. gingivalis alters the host immune response, thereby contributing to dysbiosis of the periodontal microbiome and magnifying its capacity to produce periodontitis [74].

Oral microbiome signatures have been identified for chronic periodontitis, including in gene expression, relative to the oral microbiome of periodontally healthy individuals $[75,76]$. A key question is whether stress or stress-induced biologic mediators contribute to the dysbiosis of the periodontal microbiome, impacting the initiation or progression of disease. Cortisol has been shown to significantly increase the in vitro growth of $P$. gingivalis, suggesting one mechanism underlying the association between stress and periodontal disease [77•]. Moreover, recent research has demonstrated that cortisol, when administered ex vivo, directly induces changes in the gene expression profile of the oral microbiome, consistent with previous signatures of chronic periodontitis [75••] Thus, the elevation of cortisol in saliva observed during stress, generally thought to be simply a marker of stress, actually appears to be a direct mediator of the stress-periodontitis connection [78]. The latter scenario could certainly be the case of salivary levels of pro-inflammatory cytokines induced experimentally by stress [79].

\section{Stress and Periodontitis: The Sleep Connection}

Stress and sleep have a bidirectional relationship, with cascading effects between sleep disruption and stress. In a review, Medic et al. reported that sleep disruption leads to a multitude of negative physiological effects, including activation of the HPA-axis, increased secretion of catecholamines, ACTH and cortisol, a decrease in insulin sensitivity and leptin, with a concomitant increase in ghrelin and appetite, as well as an increase in oxygen consumption and $\mathrm{CO}_{2}$ production [80]. Moreover, sleep disruption was found to be associated with an upregulation of inflammatory cytokines such as TNF- $\alpha$, 
IL-1, and IL-6, CRP, reactive oxygen species, and a decrease in the production of melatonin [80].

Sleep problems can be due to duration of sleep, sleep quality, and consistency in timing of sleep [80]. Sleep apnea is associated with the activation of the HPA axis and higher cortisol levels compared to persons without a sleep disorder [81]. Reductions in sleep time have been shown to be associated with higher reported stress levels the next day [82]. Conversely, chronic stress has been associated with reduced time spent in REM sleep [83, 84]. Early life stress is associated with insomnia $[85,86]$ and can result in increased serum concentrations of inflammatory cytokines [14, 57, 87]. Inflammatory cytokines have been found to alter and disrupt sleep [88]. Moreover, sleep disorders perpetuate the inflammatory pathway, further increasing inflammatory cytokines $[89,90]$, with potential cascading effects.

Sleep deprivation induces an increase in several biomarkers of stress, including cortisol and blood pressure [89], and leads to increased loss of alveolar bone in rat experimental models [91]. Insomnia related to stress has also been associated with periodontal disease [92]. Taken together, sleep deprivation and insomnia can be the consequence of stress and a contributor to increased vulnerability to stress, with vulnerability to infection and inflammation as one of the key mediators of the link between stress, sleep, and periodontal disease.

\section{Conclusion}

Current evidence indicates a relationship, presumably bidirectional, between stress and periodontitis, involving both dysregulation of the immune response and dysbiosis of the oral microbiome. This association underscores the importance of considering stress in the evaluation of patients with periodontitis. Patient education and referral for evaluation and counseling should be considered for patients exhibiting psychological stress or depression. A list of self-help book recommendations and referrals should be readily available. An interdisciplinaryteam approach to patient management should include consideration of a physician or mental health care practitioner.

Acknowledgments The authors thank Alexandra Dagdag for her help with the final editing and proofs of the article.

\section{Compliance with Ethical Standards}

Conflict of Interest The authors declare that they have no conflict of interest.

Human and Animal Rights and Informed Consent This article does not contain any studies with human or animal subjects performed by any of the authors.

Open Access This article is licensed under a Creative Commons Attribution 4.0 International License, which permits use, sharing, adaptation, distribution and reproduction in any medium or format, as long as you give appropriate credit to the original author(s) and the source, provide a link to the Creative Commons licence, and indicate if changes were made. The images or other third party material in this article are included in the article's Creative Commons licence, unless indicated otherwise in a credit line to the material. If material is not included in the article's Creative Commons licence and your intended use is not permitted by statutory regulation or exceeds the permitted use, you will need to obtain permission directly from the copyright holder. To view a copy of this licence, visit http://creativecommons.org/licenses/by/4.0/.

\section{References}

Papers of particular interest, published recently, have been highlighted as:

- Of importance

•- Of major importance

1. Reynolds MA. Modifiable risk factors in periodontitis: at the intersection of aging and disease. Periodontol 2000. 2014;64(1):7-19. https://doi.org/10.1111/prd.12047.

2. Cohen S, Janicki-Deverts D, Doyle WJ, Miller GE, Frank E, Rabin BS, et al. Chronic stress, glucocorticoid receptor resistance, inflammation, and disease risk. Proc Natl Acad Sci U S A. 2012;109(16): 5995-9. https://doi.org/10.1073/pnas.1118355109.

3. Cohen S, Janicki-Deverts D, Miller GE. Psychological stress and disease. JAMA. 2007;298(14):1685-7. https://doi.org/10.1001/ jama.298.14.1685.

4. Glaser R, Kiecolt-Glaser JK. Stress-induced immune dysfunction: implications for health. Nat Rev Immunol. 2005;5(3):243-51. https://doi.org/10.1038/nri1571.

5.• Netea MG, Balkwill F, Chonchol M, Cominelli F, Donath MY, Giamarellos-Bourboulis EJ, et al. A guiding map for inflammation. Nature Immunol. 2017;18(8):826-31. https://doi.org/10.1038/ni. 3790. Concise review of immunological mechanisms involved in the induction, regulation, and resolution of inflammation.

6. Johnson BD, Engel D. Acute necrotizing ulcerative gingivitis. A review of diagnosis, etiology and treatment. J Periodontol. 1986;57(3):141-50. https://doi.org/10.1902/jop.1986.57.3.141.

7. Herrera D, Retamal-Valdes B, Alonso B, Feres M. Acute periodontal lesions (periodontal abscesses and necrotizing periodontal diseases) and endo-periodontal lesions. J Clin Periodontol. 2018;45: S78-94. https://doi.org/10.1111/jcpe.12941.

8. Eke PI, Dye BA, Wei L, Slade GD, Thornton-Evans GO, Borgnakke WS, et al. Update on prevalence of periodontitis in adults in the United States: NHANES 2009 to 2012. J Periodontol. 2015;86(5):611-22. https://doi.org/10.1902/jop. 2015.140520

9. Folkman S, Lazarus RS, Dunkel-Schetter C, DeLongis A, Gruen RJ. Dynamics of a stressful encounter. Cognitive appraisal, coping, and encounter outcomes. J Pers Soc Psychol. 1986;50(5):9921003. https://doi.org/10.1037/0022-3514.50.5.992.

10. Tugade MM, Fredrickson BL. Regulation of positive emotions: emotion regulation strategies that promote resilience. J Happiness Stud. 2007;8(3):311-33. https://doi.org/10.1007/s10902-0069015-4.

11.• Danese A, Lewis SJ. Psychoneuroimmunology of early-life stress: the hidden wounds of childhood trauma? Neuropsychopharmacology. 2017;42(1):99-114. https://doi.org/10.1038/npp.2016.198. Review examines the long-term influence of early-life trauma and stress 
on the developing immune system, inflammation, and risk of psychopathology in adulthood.

12. Miller GE, Chen E. Harsh family climate in early life presages the emergence of a Proinflammatory phenotype in adolescence. Psychol Sci. 2010;21(6):848-56. https://doi.org/10.1177/ 0956797610370161.

13. Felitti VJ, Anda RF, Williamson DF, Spitz AM, Edwards V, Marks JS, et al. Relationship of childhood abuse and household dysfunction to many of the leading causes of death in adults: the Adverse Childhood Experiences (ACE) Study. Am J Prev Med. 2019;56(6): 774-86. https://doi.org/10.1016/j.amepre.2019.04.001. Study reports a strong, graded relationship between exposure to abuse or household dysfunction during childhood and risk factors for leading causes of death in adults.

14. Dube SR, Fairweather D, Pearson WS, Felitti VJ, Anda RF, Croft JB. Cumulative childhood stress and autoimmune diseases in adults. Psychosom Med. 2009;71(2):243-50. https://doi.org/10. 1097/PSY.0b013e3181907888.

15. DuMont KA, Widom CS, Czaja SJ. Predictors of resilience in abused and neglected children grown-up: the role of individual and neighborhood characteristics. Child Abuse Negl. 2007;31(3): 255-74. https://doi.org/10.1016/j.chiabu.2005.11.015.

16. Flores E, Cicchetti D, Rogosch FA. Predictors of resilience in maltreated and nonmaltreated Latino children. Dev Psyc. 2005;41(2):338-51. https://doi.org/10.1037/0012-1649.41.2.338.

17. McEwen BS. Central effects of stress hormones in health and disease: understanding the protective and damaging effects of stress and stress mediators. Eur J Pharmacol. 2008;583(2-3):174-85. https://doi.org/10.1016/j.ejphar.2007.11.071.

18. Seeman TE, McEwen BS, Rowe JW, Singer BH. Allostatic load as a marker of cumulative biological risk: MacArthur studies of successful aging. Proc Natl Acad Sci U S A. 2001;98(8):4770-5. https://doi.org/10.1073/pnas.081072698.

19. Afzal N, Thakore J. Stress axis dysfunction: a common finding in schizophrenia and the metabolic syndrome? In Thakore J, Leonard BE (eds): Metabolic Effects of Psychotropic Drugs. Mod Trends Pharmacopsychiatry. Basel, Karger. 2009;26:82-9.

20. Chandola T, Brunner E, Marmot M. Chronic stress at work and the metabolic syndrome: prospective study. BMJ. 2006;332(7540): 521-5. https://doi.org/10.1136/bmj.38693.435301.80.

21. Decker A, Askar H, Tattan M, Taichman R, Wang HL. The assessment of stress, depression, and inflammation as a collective risk factor for periodontal diseases: a systematic review. Clin Oral Investig. 2019. https://doi.org/10.1007/s00784-019-03089-3. Review addresses the interconnection between stress, depression, and inflammation and the potential for the combination of these factors to impact risk for periodontal diseases.

22. Guerry JD, Hastings PD. In search of HPA Axis Dysregulation in child and adolescent depression. Clin Child Fam Psychol Rev. 2011;14(2):135-60. https://doi.org/10.1007/s10567-011-0084-5.

23. Heim C, Newport DJ, Mletzko T, Miller AH, Nemeroff CB. The link between childhood trauma and depression: Insights from HPA axis studies in humans. Psychoneuroendocrinology. 2008;33(6): 693-710. https://doi.org/10.1016/j.psyneuen.2008.03.008.

24. Joels M, Baram TZ. The neuro-symphony of stress. Nat Rev Neurosci. 2009;10(6):459-66. https://doi.org/10.1038/nrn2632.

25. Kessler RC. The effects of stressful life events on depression. Ann Rev Psychol. 1997;48(1):191-214. https://doi.org/10.1146/ annurev.psych.48.1.191.

26. Leserman J, Petitto JM, Golden RN, Gaynes BN, Gu H, Perkins DO, et al. Impact of stressful life events, depression, social support, coping, and cortisol on progression to AIDS. Am J Psychiatry. 2000;157(8):1221-8. https://doi.org/10.1176/appi.ajp.157.8.1221.

27. Marsland AL, Bachen EA, Cohen S, Rabin B, Manuck SB. Stress, immune reactivity and susceptibility to infectious disease. Physiol
Behav. 2002;77(4-5):711-6. https://doi.org/10.1016/s00319384(02)00923-x.

28. Parwani R, Parwani SR. Does stress predispose to periodontal disease? Dent Update. 2014;41(3):260-4, 7-8, 71-2. https://doi.org/ 10.12968/denu.2014.41.3.260.

29. Yehuda R, Seckl J. Minireview: stress-related psychiatric disorders with low cortisol levels: a metabolic hypothesis. Endocrinol. 2011;152(12):4496-503. https://doi.org/10.1210/en.2011-1218.

30. Genco RJ, Ho AW, Grossi SG, Dunford RG, Tedesco LA. Relationship of stress, distress, and inadequate coping behaviors to periodontal disease. J Periodontol. 1999;70(7):711-23. https:// doi.org/10.1902/jop.1999.70.7.711.

31.• Coelho JMF, Miranda SS, da Cruz SS, Trindade SC, Passos-Soares JS, Cerqueira EMM, et al. Is there association between stress and periodontitis? Clin Oral Investig. 2019. https://doi.org/10.1007/ s00784-019-03083-9. Cross-sectional study shows a positive association between stress and perioodontitis, independent of other factors, such as smoking.

32. Croucher R, Marcenes WS, Torres MC, Hughes F, Sheiham A. The relationship between life-events and periodontitis. A case-control study. J Clin Periodontol. 1997;24(1):39-43. https://doi.org/10. 1111/j.1600-051x.1997.tb01182.x.

33. Dolic M, Bailer J, Staehle HJ, Eickholz P. Psychosocial factors as risk indicators of periodontitis. J Clin Periodontol. 2005;32(11): 1134-40. https://doi.org/10.1111/j.1600-051X.2005.00838.x.

34. Freeman R, Goss S. Stress measures as predictors of periodontal disease - a preliminary communication. Community Dent Oral Epidemiol. 1993;21(3):176-7. https://doi.org/10.1111/j.16000528.1993.tb00748.x.

35. Green LW, Tryon WW, Marks B, Huryn J. Periodontal disease as a function of life events stress. J Hum Stress. 1986;12(1):32-6. https://doi.org/10.1080/0097840X.1986.9936764.

36.• Coelho JMF, Miranda SS, da Cruz SS, Trindade SC, Passos-Soares JS, Cerqueira EMM, et al. Is there association between stress and periodontitis? Clin Oral Investig. 2020;24(7):2285-94. https://doi. org/10.1007/s00784-019-03083-9. Crosssectional study showed a positive association between exposure to stress and the presence of periodontitis, after adjustment for age, sex, education, current smoking, pulmonary disease, and body mass index.

37. Appukuttan DP. Strategies to manage patients with dental anxiety and dental phobia: literature review. Clin Cosmet Investig Dent. 2016;8:35-50. https://doi.org/10.2147/CCIDE.S63626.

38.• Blander JM, Longman RS, Iliev ID, Sonnenberg GF, Artis D. Regulation of inflammation by microbiota interactions with the host. Nat Immunol. 2017;18(8):851-60. https://doi.org/10.1038/ ni.3780. Review examines the effects of the intestinal microbiome on innate and adaptive immune responses as well as the effects of microbiota-derived bioactive molecules on inflammation.

39.• Godoy LD, Rossignoli MT, Delfino-Pereira P, Garcia-Cairasco N, de Lima Umeoka EH. A comprehensive overview on stress neurobiology: basic concepts and clinical implications. Front Behav Neurosci. 2018;12(127). https://doi.org/10.3389/fnbeh.2018. 00127. Review presents a comprehensive overview of stress neurobiology as well as the clinical implications of dysregulation of the stress system.

40. Mulkey SB, du Plessis AJ. Autonomic nervous system development and its impact on neuropsychiatric outcome. Pediatr Res. 2019;85(2):120-6. https://doi.org/10.1038/s41390-018-0155-0. Review presents an overview of autonomic nervous system development and maturation, including aspects influenced by activation of the central stress response (HPA axis) and glucocorticoids, that have been related to neuropsychiatric outcomes in children. 
41. Ramot A, Jiang Z, Tian J-B, Nahum T, Kuperman Y, Justice N, et al. Hypothalamic CRFR1 is essential for HPA axis regulation following chronic stress. Nat Neurosci. 2017;20(3):385-8. https:// doi.org/10.1038/nn.4491.

42. Won E, Kim Y-K. Stress, the autonomic nervous system, and the immune-kynurenine pathway in the etiology of depression. Curr Neuropharmacol. 2016;14(7):665-73. https://doi.org/10.2174/ 1570159x14666151208113006.

43. Chrousos GP. Stress and disorders of the stress system. Nat Rev Endocrinol. 2009;5(7):374-81. https://doi.org/10.1038/nrendo. 2009.106.

44. Silverman MN, Sternberg EM. Glucocorticoid regulation of inflammation and its functional correlates: from HPA axis to glucocorticoid receptor dysfunction. Ann N Y Acad Sci. 2012;1261:5563. https://doi.org/10.1111/j.1749-6632.2012.06633.x. Review examines the role of impairments in the stress response (HPA axis activity), including hypocortisolism and glucocorticoid resistance, and enhanced susceptibility to inflammatory and autoimmune diseases.

45. Reiche EM, Nunes SO, Morimoto HK. Stress, depression, the immune system, and cancer. Lancet Oncol. 2004;5(10):617-25. https://doi.org/10.1016/S1470-2045(04)01597-9.

46. Goldstein DS. Adrenal responses to stress. Cell Mol Neurobiol. 2010;30(8):1433-40. https://doi.org/10.1007/s10571-010-9606-9.

47. Hilgert JB, Hugo FN, Bandeira DR, Bozzetti MC. Stress, cortisol, and periodontitis in a population aged 50 years and over. J Dent Res. 2006;85(4):324-8. https://doi.org/10.1177/ 154405910608500408 .

48. Leserman J, Pence BW, Whetten K, Mugavero MJ, Thielman NM, Swartz MS, et al. Relation of lifetime trauma and depressive symptoms to mortality in HIV. Am J Psychiatry. 2007;164(11):1707-13. https://doi.org/10.1007/s10571-010-9606-9.

49. Hofer MA, Wolff CT, Friedman SB, Mason JW. A psychoendocrine study of bereavement: part I. 17Hydroxycorticosteroid excretion rates of parents following death of their children from leukemia. Psychosom Med. 1972;34(6): 481-91. https://doi.org/10.1097/00006842-197211000-00001.

50. Segerstrom SC, Miller GE. Psychological stress and the human immune system: a meta-analytic study of 30 years of inquiry. Psychol Bull. 2004;130(4):601-30. https://doi.org/10.1037/00332909.130.4.601.

51. Haroon E, Raison CL, Miller AH. psychoneuroimmunology meets neuropsychopharmacology: translational implications of the impact of inflammation on behavior. Neuropsychopharmacology. 2012;37(1):137-62. https://doi.org/10.1038/npp.2011.205.

52. Yang J, Wu J, Liu Y, Huang J, Lu Z, Xie L, et al. Porphyromonas gingivalis infection reduces regulatory $\mathrm{T}$ cells in infected atherosclerosis patients. PloS One. 2014;9(1):e86599-e. https://doi.org/ 10.1371/journal.pone.0086599.

53. Lu H, Xu M, Wang F, Liu S, Gu J, Lin S. Chronic stress enhances progression of periodontitis via alpha1-adrenergic signaling: a potential target for periodontal disease therapy. Exp Mol Med. 2014;46:e118. https://doi.org/10.1038/emm.2014.65. Experimental animal model suggests that chronic stress contributes to the progression of periodontitis by an $\alpha 1-$ adrenergic signaling-mediated inflammatory response.

54. Takada T, Yoshinari N, Sugiishi S, Kawase H, Yamane T, Noguchi $\mathrm{T}$. Effect of restraint stress on the progression of experimental periodontitis in rats. J Periodontol. 2004;75(2):306-15. https://doi.org/ 10.1902/jop.2004.75.2.306.

55. Peruzzo DC, Benatti BB, Ambrosano GMB, Nogueira-Filho GR, Sallum EA, Casati MZ, et al. A systematic review of stress and psychological factors as possible risk factors for periodontal disease. J Periodontol. 2007;78(8):1491-504. https://doi.org/10. 1902/jop.2007.060371.
56. Botelho J, Machado V, Mascarenhas P, Rua J, Alves R, Cavacas MA, et al. Stress, salivary cortisol and periodontitis: a systematic review and meta-analysis of observational studies. Arch Oral Biol. 2018;96:58-65. https://doi.org/10.1016/j.archoralbio.2018.08.016.

57. Bauer ME, Wieck A, Lopes RP, Teixeira AL, Grassi-Oliveira R. Interplay between neuroimmunoendocrine systems during posttraumatic stress disorder: a minireview. Neuroimmunomodulation. 2010;17(3):192-5. https://doi.org/10.1159/000258721.

58. Gárate I, Garcia-Bueno B, Madrigal JLM, Caso JR, Alou L, Gomez-Lus ML, et al. Stress-induced Neuroinflammation: role of the toll-like Receptor-4 pathway. Biol Psychiatry. 2013;73(1):3243. https://doi.org/10.1016/j.biopsych.2012.07.005.

59. Graham JE, Christian LM, Kiecolt-Glaser JK. Stress, age, and immune function: toward a lifespan approach. J Behav Med. 2006;29(4):389-400. https://doi.org/10.1007/s10865-006-9057-4.

60. Herbert TB, Cohen S. Stress and immunity in humans: a metaanalytic review. Psychosom Med. 1993;55(4):364-79. https://doi. org/10.1097/00006842-199307000-00004.

61. Merlot E, Couret D, Otten W. Prenatal stress, fetal imprinting and immunity. Brain Behav Immun. 2008;22(1):42-51. https://doi.org/ 10.1016/j.bbi.2007.05.007.

62. Nakata A. Psychosocial job stress and immunity: a systematic review. In: Yan Q, editor. Psychoneuroimmunology: methods and protocols. Totowa: Humana Press; 2012. p. 39-75.

63. Steptoe A, Hamer M, Chida Y. The effects of acute psychological stress on circulating inflammatory factors in humans: a review and meta-analysis. Brain Behav Immun. 2007;21(7):901-12. https:// doi.org/10.1016/j.bbi.2007.03.011.

64. Masada MP, Kenney JS, Lee SW, Allison AC, Persson R, Page RC. Measurement of interleukin- $1 \alpha$ and $-1 \beta$ in gingival crevicular fluid: implications for the pathogenesis of periodontal disease. J Periodontal Res. 1990;25(3):156-63. https://doi.org/10.1111/j. 1600-0765.1990.tb01038.x.

65. Page RC. The role of inflammatory mediators in the pathogenesis of periodontal disease. J Periodontal Res. 1991;26(3):230-42. https:// doi.org/10.1111/j.1600-0765.1991.tb01649.x.

66. Manouchehr-Pour M, Spagnuolo PJ, Rodman HM, Bissada NF. Comparison of neutrophil chemotactic response in diabetic patients with mild and severe periodontal disease. J Periodontol. 1981;52(8):410-5. https://doi.org/10.1902/jop.1981.52.8.410.

67. Hajishengallis G, Lamont RJ. Breaking bad: manipulation of the host response by porphyromonas gingivalis. Eur J Immunol. 2014;44(2):328-38. https://doi.org/10.1002/eji.201344202.

68. Wadhawan AR, Reynolds MA, Makkar H, Scott AJ, Potocki E, Hoisington AJ, et al. Periodontal pathogens and neuropsychiatric health. Curr Top Med Chem. 2020. https://doi.org/10.2174/ 1568026620666200110161105 Review summarizes current evidence on the association between Porphyromonas gingivalis and neruopsychiatric health as well as potential underlying mechanisms of bacterial pathogenicity.

69. Deng Z-L, Sztajer H, Jarek M, Bhuju S, Wagner-Döbler I. Worlds apart - transcriptome profiles of key Oral microbes in the periodontal pocket compared to single laboratory culture reflect synergistic interactions. Front Microbiol. 2018;9:124. https://doi.org/10.3389/ fmicb.2018.00124.

70. Socransky SS, Haffajee AD, Cugini MA, Smith C, Kent RL Jr. Microbial complexes in subgingival plaque. J Clin Periodontol. 1998;25(2):134-44. https://doi.org/10.1111/j.1600-051x.1998. tb02419.x.

71. Almerich-Silla JM, Montiel-Company JM, Pastor S, Serrano F, Puig-Silla M, Dasí F. Oxidative stress parameters in saliva and its association with periodontal disease and types of Bacteria. Dis Markers. 2015;2015:653537. https://doi.org/10.1155/2015/ 653537. 
72. Hajishengallis G, Darveau RP, Curtis MA. The keystone-pathogen hypothesis. Nature Rev Microbiol. 2012;10(10):717-25. https:// doi.org/10.1038/nrmicro2873.

73. Ardila CM, Guzman IC. Association of Porphyromonas gingivalis with high levels of stress-induced hormone cortisol in chronic periodontitis patients. J Investig Clin Dent. 2016;7(4):361-7. https:// doi.org/10.1111/jicd.12175.

74. Costalonga M, Herzberg MC. The oral microbiome and the immunobiology of periodontal disease and caries. Immunol Lett. 2014;162(2 Pt A):22-38. https://doi.org/10.1016/j.imlet.2014.08. 017.

75.• Duran-Pinedo AE, Solbiati J, Frias-Lopez J. The effect of the stress hormone cortisol on the metatranscriptome of the oral microbiome. Npj Biofilms and Microbiomes. 2018;4(1):25. https://doi.org/10. 1038/s41522-018-0068-z. Study demonstrates that cortisol directly induces shifts in gene expression profiles of the oral microbiome that reproduce shifts in gene expression observed in periodontal disease and progression.

76. Yost S, Duran-Pinedo AE, Teles R, Krishnan K, Frias-Lopez J. Functional signatures of oral dysbiosis during periodontitis progression revealed by microbial metatranscriptome analysis. Genom Medicine. 2015;7(1):1-19. https://doi.org/10.1186/s13073-0150153-3.

77. Akcali A, Huck O, Buduneli N, Davideau JL, Kose T, Tenenbaum $\mathrm{H}$. Exposure of Porphyromonas gingivalis to cortisol increases bacterial growth. Arch Oral Biol. 2014;59(1):30-4. https://doi.org/10. $1016 /$ j.archoralbio.2013.09.003. Study shows that cortisol directly induces an increase the the growth of $\boldsymbol{P}$. gingivalis in vitro.

78. Akcali A, Huck O, Tenenbaum H, Davideau JL, Buduneli N. Periodontal diseases and stress: a brief review. J Oral Rehabil. 2013;40(1):60-8. https://doi.org/10.1111/j.1365-2842.2012. 02341.x.

79. Slavish DC, Szabo YZ. The effect of acute stress on salivary markers of inflammation: a systematic review protocol. Syst Rev. 2019;8(1):108. https://doi.org/10.1186/s13643-019-1026-4.

80. Medic G, Wille M, Hemels ME. Short- and long-term health consequences of sleep disruption. Nat Sci Sleep. 2017;9:151-61. https://doi.org/10.2147/NSS.S134864.

81. Trakada G, Chrousos G, Pejovic S, Vgontzas A. Sleep apnea and its association with the stress system, inflammation, insulin resistance and visceral obesity. Sleep Med Clin. 2007;2(2):251-61. https:// doi.org/10.1016/j.jsmc.2007.04.003.

82. Yap Y, Slavish DC, Taylor DJ, Bei B, Wiley JF. Bi-directional relations between stress and self-reported and actigraphy-assessed sleep: a daily intensive longitudinal study. Sleep. 2019;43. https:// doi.org/10.1093/sleep/zsz250.
83. Nollet M, Hicks H, McCarthy AP, Wu H, Möller-Levet CS, Laing EE, et al. REM sleep's unique associations with corticosterone regulation, apoptotic pathways, and behavior in chronic stress in mice. Proc Natl Acad Sci U S A. 2019;116(7):2733-42. https://doi.org/ 10.1073/pnas.1816456116.

84. Sanford LD, Fang J, Tang X. Sleep after differing amounts of conditioned fear training in BALB/cJ mice. Behav Brain Res. 2003;147(1):193-202. https://doi.org/10.1016/S0166-4328(03) 00180-3.

85. Lo Martire V, Caruso D, Palagini L, Zoccoli G, Bastianini S. Stress \& sleep: a relationship lasting a lifetime. Neurosci Biobehav Rev. 2019. https://doi.org/10.1016/j.neubiorev.2019.08.024.

86. Palagini L, Drake CL, Gehrman P, Meerlo P, Riemann D. Early-life origin of adult insomnia: does prenatal-early-life stress play a role? Sleep Med. 2015;16(4):446-56. https://doi.org/10.1016/j.sleep. 2014.10.013.

87. Slopen N, Kubzansky LD, McLaughlin KA, Koenen KC. Childhood adversity and inflammatory processes in youth: a prospective study. Psychoneuroendocrinology. 2013;38(2):188-200. https://doi.org/10.1016/j.psyneuen.2012.05.013.

88. Krueger JM. The role of cytokines in sleep regulation. Curr Pharm Des. 2008;14(32):3408-16. https://doi.org/10.2174/ 138161208786549281.

89. Besedovsky L, Lange T, Haack M. The sleep-immune crosstalk in health and disease. Physiol Rev. 2019;99(3):1325-80. https://doi. org/10.1152/physrev.00010.2018.

90. Karaaslan F, Dikilitas A. The association between stage-grade of periodontitis and sleep quality and oral health-related quality of life. J Periodontol. 2019;90(10):1133-41. https://doi.org/10.1002/jper. 19-0034. Study shows that periodontitis is associated with short sleep duration and low-sleep quality, suggesting a bidirectional relationship between sleep disorders and periodontal disease.

91. Nakada T, Kato T, Numabe Y. Effects of fatigue from sleep deprivation on experimental periodontitis in rats. J Periodontal Res. 2015;50(1):131-7. https://doi.org/10.1111/jre.12189.

92. Tsuchiya M, Aida J, Hagiwara Y, Sugawara Y, Tomata Y, Sato M, et al. Periodontal disease is associated with insomnia among victims of the great East Japan earthquake: a panel study initiated three months after the disaster. Tohoku J Exp Med. 2015;237(2):83-90. https://doi.org/10.1620/tjem.237.83.

Publisher's Note Springer Nature remains neutral with regard to jurisdictional claims in published maps and institutional affiliations. 